\title{
Adapting PMBoK Guidance to Public Sector Projects
}

DOI 10.5592/otmcj.2014.3.3

Research paper

Keywords
Project Management Body
of Knowledge Guide,
Scalable,
Change Management,
Requirements,
Work Breakdown Structure

\author{
Fred Eldridge Fanning \\ Project Management Institute \\ 3 Chandler Court \\ Fredericksburg, \\ fredefanning@gmail.com
}

IT IS THE AUTHOR'S EXPERIENCE THAT MANY EMPLOYEES OF THE United States GoVernment MANAge PROJeCtS Without adeQUATE STANDARDS OR TRAINING. Many of these projects fail, which is unfortunate, because the Project Management Institute has developed standards and a body of knowledge to help anyone manage projects successfully. Adapting the Project Management Institute's standards to a government organization and conducting training for government project managers based on the Project Management Body of Knowledge leads to increased potential for projects to be managed properly. The author was involved in a government organization where this was done. In this technical paper, the author explains how standards were adapted; training was identified, and projects classified leading to successful project management in that organization. The results were so successful that the author implemented them again in a new organization he was hired to lead.

Project Management Body of Knowledge Guide - is the recognized body of knowledge on the management of projects that is written and updated by the Project Management Institute.

Scalable - developing a solution that can be used for various sized problems in direct proportion to the size of the problem.

Change Management - describes the management of change in organizations or the implementation of a management process to ensure that change is managed efficiently and effectively. Requirements - specific parameters that a project must deliver to.

Work Breakdown Structure - work list that describes all the work to be accomplished down to the work package level. 


\section{INTRODUCTION}

Over the years, the author has seen employees of the United States Government manage projects without adequate training or experience and in many cases the projects failed. This was unfortunate for both the employees and the project stakeholders. It is beneficial to have procedures in the government that standardize project management. These procedures should be followed and all personnel involved in the project should be properly trained to those standards. This leads to projects that are properly managed and successful (Fanning, 2011). Based on the author's experience in the United States government most projects are not managed in accordance with the Project Management Institute's Body of Knowledge (PMBoK), but rather by a home grown or personally created standards and procedures. Things are changing. In this technical paper, the author outlines how people from one federal agency adapted the PMBoK guidance to how an office managed projects and familiarized their employees to the adapted standards. Since the author is a government employee, it is important to note that the statements made in this paper are the author's and not the United States Government or the agency in which the adaptation was done.

An office in a government agency had problems implementing projects on time, to standard, and within budget. Through an evaluation of the processes this office used to manage projects it was determined that the problems were caused by a lack of standard project management processes and poorly trained project managers (PM). A Senior IT manager was tasked with developing and implementing project management processes to correct the problems identified in the evaluation. The Senior IT Manager and his staff worked with others in the office to develop a scalable process for project management. The program consisted of:
Classifying projects according to time and cost

Defining the role of the PM within the office

$\checkmark$ Identifying PM training

- Adapting procedures for change management

- Adapting procedures for developing project requirements

- Adapting procedures for using work breakdown structures

The Senior IT Manager was familiar with the Project Management Institutes (PMI) PMBoK. This made it an easy decision to use this as the basis for the project management processes (Fanning, 2013). The author of this paper was an employee in the office where this occurred and later was assigned to lead a large office and found similar project management issues in that office. The author used the process developed by the IT Manager and implemented an effective project management process in his new organization, as well. Having seen the processes work twice, the author believes it could work in many other government offices.

\section{Project Classification}

"A scalable process was developed to classify projects so that the level of effort equated to the cost of the project. Three levels were used that began with basic, Level 1, and ended with complex, Level 3" (Fanning, 2013).

- Level 1 Projects have a budget under $\$ 100,000$, a project team with less than two full-time members, completion time under six months; existing examples of very similar projects, and low risk exposure (OHRM, 2006).

- Level 2 Projects have a budget between $\$ 100,000$ and $\$ 300,000$, a project team with two or three full-time members, completion time between six and twelve months, a department-wide scope and impact, and moderate risk exposure (OHRM, 2006).

- Level 3 Projects have a budget over $\$ 300,000$, a project team with more than three full-time members; a completion time exceeding one-year; a wide scope and impact, and high risk exposure (OHRM, 2006).

In this type of office, most projects were Level 1. There were occasions that a Level 2 or 3 projects were managed, but not very often. Two particular occasions when level 3 projects occurred were the second generation online learning and hiring action program projects. Both projects had an agency wide impact, several full-time team members, both were determined to have high risk, and a cost over $\$ 500,000$.

\section{Project Manager Requirements}

> After determining the specific levels of projects, the IT Manager turned his attention to identifying how best to ensure each project was led by a trained and appointed PM. It was decided that PMs had to be properly trained, but not overly trained to save money. This meant training for PMs had to be scalable too. The final result was that PMs were trained to oversee specific levels of projects (Fanning, 2013). Within the analysis the PM was identified as the person that fulfilled the following roles:

Responsible for managing the overall project and its deliverables

- Acts as the customers' single point of contact for the project

- Controls planning and execution to ensure that established cost, time, and quality goals are met (Fanning, 2011)

As mentioned earlier, projects were classified at three levels. PMs were also trained to those same levels from novice, Level 1 to most capable, Level 3. This ensured the PM was working on a project they were trained to manage; however, it was not cost effective to train all PMs to lead the most complex projects since they occurred infrequently. Through trial and error it was determined that: 
Level 1 PMs should complete basic training in project management (see next section for more on basic training).

- Level 2 PMs should complete basic training in project management, a university basic level certificate program, and have 12 or more months of experience managing Level 1 projects.

- Level 3 PMs should complete basic training in project management; a university advanced level certificate, and have 48 or more months experience managing Level 2 projects. (OAS, 2006)

\section{Basic Project Manager Training} Specific training that should be completed by each PM was identified based on the level of the projects the PM would manage. Instructor led and computer based training were found that covered the topics needed to do the job properly. Several topic areas were often included in a single course. All of the courses were part of the PM curriculum within a learning path (A Guide, 2005). Extensive use was made of the agency's online learning center that delivered PMBoK aligned courses. The intent was for the Level 1 PM to complete basic training in project management and for Levels 2 and 3 to build on that basic knowledge. The topic areas identified for each level were:

$\checkmark$ Level 1 project PMs should be trained in the following:

- Planning a Project

- Controlling and Closing a Project

- Integrating a Project

- Project Scope

- Project Time Management

- Project Cost Management

- Project Quality Management

- Human Resource Management

- Project Communication Management

- Project Risk Management

- Project Procurement Management

- Level 2 PMs had to complete the basic training for a Level 1 PM plus the following:
- Building Productive Stakeholder Relationships

- Managing Accelerated Projects

- Project Management Maturity

- Overcoming Obstacles

- Level 3 PMs had to complete training in all the areas for a Level 1 and 2 PM plus the following:

- Organization, Strategy, and

Business Needs

- Navigating Corporate Structures (OAS, 2006)

The IT Manager also collaborated with a training provider and local university to provide classroom training leading to basic and advanced certificates in Project Management. The cost for either certificate was approximately $\$ 5,000$ and was paid for by the office. These certificates were determined to be the best route to complete training if time and money are available. The goal was for anyone completing the advanced certificate to sit for the PMP $®$ examination. Some did and passed, but most never took that extra step.

\section{Project Requirements}

"Now that the project and PM levels were determined the IT Manager found it essential to determine the requirements for each level of project. The goal was to make them scalable to get the most information at the lowest cost" (Fanning, 2013). "The following requirements represented standards for each project level; however, alterations were acceptable and often necessary for unique project situations" (Fanning, 2011).

- Level 1 Projects could be assigned to Level 1, 2, or 3 PM; however, the cost effective assignment was for the Level 1 PM to be assigned to a Level 1 project. The minimum documentation required included a status update form, approved statement of need, list of key stakeholders, Work Breakdown Structure (WBS), procurement requests, and lessons learned. A bi-weekly written status report was the only necessary report. There were two presentations, project initiation and closeout, that were required (OAS, 2006).

- Level 2 Projects could be assigned to a Level 2 or 3 PM; however, the cost effective assignment was for the Level 2 PM to be assigned to a Level 2 project. The minimum documentation required included a status update form, approved business case, project charter, requirements analysis, communication plan, WBS, risk assessment, change control plan, deliverables sign-off, procurement requests and contracts, and lessons learned. A bi-weekly written status report and the compliance with project communication report were the only reports needed. There were two presentations, project initiation and closeout, that were required (OAS, 2006).

- Level 3 Projects could only be assigned to Level 3 PM. The minimum documentation required included the project management plan, status update form, approved business case, project charter, requirements analysis, communication plan, WBS, risk assessment, earned value management plan, change control plan, deliverables sign-off and inspection test plan, procurement requests and contracts, and lessons learned. A biweekly written status report and the compliance with project communication report were the only reports needed. There were two presentations, project initiation and closeout, that were required (OAS, 2006).

To further the standardization, PMs received templates for each of the documents to help facilitate the process. The project update was a scheduled time for PMs to provide a 'pulse check' on current status and activities to the project sponsor (Fanning, 2013). Each presentation was intended for a high-level and restricted to no more than five to seven minutes for a Level 1 project, seven to ten minutes for Level 
2 project, and 10 to 15 minutes for Level 3 project (Fanning, 2011).

\section{Change Management Plan}

Level 2 and 3 projects required a Change Management Plan to ensure that changes were properly reviewed and approved. An informal process was found to be best for change management at Level 1. It was determined that Level 2 and 3 projects needed to have a change management plan because of the potential cost in money and time if not managed properly. Changes were also coordinated across the entire project team (Fanning, 2013). The goals of a Change Management Plan were:

Identify, define, evaluate, approve, and track changes

> Bring the relevant stakeholders into the discussion

> Negotiate changes and communicate them to affected stakeholders

- Give due consideration to change requests

Modify plans to reflect changes (OHRM, 2006)

The Change Management process was intended to be scalable and included the following steps (A Guide, 2005):

- Submit change request in writing

$\checkmark$ Review change request

- Approve change request

Reject change request for further review

- If approved, perform analysis and develop a recommendation

If rejected, return to submitter

- Accept or reject the recommendation

- If accepted, update documents and re-plan

- If rejected, return to submitter

- Notify all stakeholders of the change

"Change requests were reviewed daily by the PM and assigned one of four possible outcomes:

$>$ rejected,

$>$ deferred to a future date,

$>$ accepted, or

> set aside until additional information is received" (Fanning, 2013).

\section{Work Breakdown Structure (Wbs)}

Each project required a WBS. The minimum information that was required on the WBS included:

a task list,

dates of each task,

- days each task should take,

$\checkmark$ resources used by each task, and

$\checkmark$ milestones for the project (PMBoK®, 2005).

PMs could document the WBS by hand for simple projects, use Microsoft Excel $\circledast$ spreadsheets for more complex projects, or use Microsoft Project ${ }^{\circledR}$ for very complex projects. Microsoft Excel $\circledast$ and Project $\circledast$ were provided to all PMs. Some used Microsoft Project ${ }^{\circledR}$, but more used Microsoft Excel®.

\section{Changes For The Second Implementation}

When the author implemented this process in another office, he made very few changes. He did update and add training courses as well as some options for training. After a careful review the author added the following courses:

- For the Level 1 PMs:

- Project Scheduling and Budgeting

- Project Management Framework

- Project Management Process

-Project Scheduling and Budgeting

- For the Level 2 PMs:

- Project Estimating Techniques

- Leading the Project Team

- Communicating Within a Project Team

For the Level 3 PMs:

- Portfolio Management

- Bringing Home the Value

- Selling Project Management to the Organization (OAS, 2006)

Level 2 PM were provided the option to be certified as a Certified Associate Project Manager (CAPM $®$ ) through the Project Management Institute in lieu of completing the university basic level certificate program. Level 3 PM were provided the option to be certified as a Project Management Professional (PMP®) through Project Management Institute in lieu of completing the university advanced level certificate program. The organization paid the cost of either decision (Fanning, 2011).

\section{Summary}

The author noticed that United States Government employees were usually not trained to manage projects and because of this many failed. Furthermore, no standard project management standard was being used. This is unfortunate because the Project Management Institute has developed standards and a body of knowledge to help anyone called upon to manage a project. Most government employees don't need to be an expert in project management, but they do need to know how to manage a project. In this technical paper, the author outlined how a government agency adapted the Project Management Institutes project management standards and from that identified the appropriate levels of training that should be provided to government employees to familiarize them with the basic information needed to manage a project. Armed with this information standards were implemented and the government employees received the needed training. After careful review the author determined the reason most PMs didn't use Microsoft Project $®$ as often was Microsoft Excel $\circledast$ because no training was provided in how to use it. In future application it would be essential to add this training at the Level 1 PM. This would seem, logically, to lead to more use. All this work led to positive results in successful project management for two government offices; however, it could help many other offices and be very effective in construction projects. 


\section{References}

A Guide to the Project Management Body of Knowledge, Third Edition (PMBoK® $5^{\text {th }}$ Ed), (ANSI Standard 99-001-2005), Project Management Institute, 2013.

Fanning, F.E. (2013). “Adapting PMBoK Guidance for Human Resources Projects", PMI GovCOP Magazine, June 2013 edition, pp. 88-93.

Fanning, F.E. (2011). "Essay 30-Project Management for SHE Professionals", Essays on Safety, Health, and Environment, CreateSpace, Charleston, SC, pp. 158-165.

OAS, Office of Administrative Services, US Department of Commerce, Project Management Guidelines, August 2006.

OHRM, Office of Human Resources Management, US Department of Commerce, Project Management Guidelines, January 2006. 